\title{
Teaching Freshman Design Using a Flipped Classroom Model
}

Dr. Ann Saterbak, Rice University

Dr. Matthew Wettergreen, Rice University 


\title{
Teaching Freshman Design Using a Flipped Classroom Model
}

\begin{abstract}
A team of faculty at Rice University and other institutions are creating instructional resources to support a flipped classroom for first-year engineering design. The traditional 'class' in which faculty lecture on the design process has been replaced by in-class exercises and additional team time. Since the flipped classroom model shifts course content with low cognitive load to videos, students learn this material outside of the classroom. Now, students spend even more time during class applying the design process to their projects. For example, teams develop appropriate design criteria, brainstorm and select a design solution, and build physical prototypes during class.

The first objective of this project is to create educational materials to flip the first-year multidisciplinary engineering design classroom. To date, we have completed a substantial library of videos, associated quizzes, and in-class exercises. The second objective of this project is to answer the engineering education research question: Are there differences in student performance in executing the engineering design process when comparing delivery of engineering design process knowledge using a lecture format versus a flipped classroom model?
\end{abstract}

The team is seeking feedback on materials that will be helpful for the academic community teaching engineering design. This work is supported by NSF DUE grant \#1244928.

\section{Flipped Classroom Model}

A new curriculum model, known as the flipped classroom model, has emerged that inverts the traditional instructor-centered, lecture-based approach. This model takes advantage of easy access to video and the internet and addresses changing educational needs of students. The flipped classroom model shifts course content with low cognitive load outside of the classroom, thus freeing class time for students to focus on high cognitive load tasks such as design. ${ }^{1,2}$

In the flipped classroom, faculty commit to use multimedia technology to deliver time-shifted content via audio podcasts, screencasts, and other forms of rich media. To prepare for a flipped classroom, students complete "homework" that involves watching videos or listening to audio podcasts. During class time, teachers lead students to discover, apply, and then explain important concepts to each other. This active learning classroom model is consistent with best practices in engineering education. ${ }^{3-6}$

K-12 STEM teachers have been early adopters of the flipped classroom. More recently, university STEM faculty have adopted this method, particularly in large, lower-level courses. During the past few years, as more faculty adopt flipped classrooms at the university level, there is a growing body of peer-reviewed literature about the efficacy of this method. ${ }^{1,2,-10} \mathrm{We}$ are seeking to contribute to this literature in the area of engineering design. 


\section{Motivation and Overall Project Aims}

In our comprehensive review of materials in 2012, no publicly available videos existed for teaching the engineering design process at any undergraduate level. Creating flipped classroom materials for our first-year engineering design course was driven by our commitment to adopting this model in the absence of any existing materials. Our literature review also found no completed assessment on the impact of the flipped classroom model on an undergraduate engineering design course.

Building on best practices in engineering education, faculty at Rice University are creating educational resources to support a flipped classroom model for first-year multidisciplinary engineering design. Our funded NSF proposal (DUE grant \#1244928) seeks to address the following three specific aims:

Specific Aim \#1 Develop flipped classroom instructional materials for sections of the design process including design criteria, brainstorming and evaluation solutions, and initial prototyping.

Specific Aim \#2 Assess the effectiveness of the flipped classroom model for a first-year engineering design course.

Specific Aim \#3 Collaborate and partner with the first-year engineering community to receive critical formative feedback on materials and then disseminate developed materials.

Introduction to Engineering Design (ENGI 120) is a one-semester multidisciplinary design course for freshman students at Rice University. In ENGI 120, students learn the engineering design process and use it to solve meaningful problems drawn from local hospitals, local community partners, international communities, and around the university campus. The course outcomes, structure, and deliverables have been described in detail elsewhere. ${ }^{11}$ From spring 2011 through spring 2014, ENGI 120 was taught using a lecture/team meeting model. During each class period, students listened to a lecture and also worked in their team on their design project. In fall 2014 and forward, ENGI 120 is being taught using the flipped/team meeting model using the materials described herein. Students participate in all aspects of the flipped model (video and quiz before class; in-class exercises replacing lectures) and also work with their design team on their challenge. Details on the format for the flipped/team meeting model is described elsewhere. ${ }^{12}$

\section{Status of Specific Aim \#1 - Creation of Educational Materials}

The first thrust of this project is to create educational materials to transfer the delivery of content regarding the design process to an out-of-class environment and to develop in-class active learning modules that clarify, elaborate, and expand on critical design process topics. To date, nine modules have been created. Each module includes a playlist of several videos, one or two online quizzes, and three in-class exercises.

- Pairwise comparison charts

- Design criteria

- User-defined scales (design criteria)
- Decomposition

- Morphological charts

- Brainstorming 
- Pugh screening matrix

- Gantt charts

- Pugh scoring matrix

\section{Videos}

Within these nine modules, we have completed 32 web-based videos that are 1-11 min in length. The videos feature student teams and faculty at Rice University and other institutions who teach, explain, and illustrate the steps of the engineering design process. The instructional videos are a mixture of the instructor talking, the instructor talking with text placed to the side, and slideshow panels (text, table, picture, etc.). Example videos have been made by Rice engineering design teams based on their ENGI 120 projects. Most of these playlists can be found online at http://goo.gl/YF78TY.

\section{Quizzes}

Online quizzes are used to monitor students' understanding of the information in the videos. A series of multiple choice questions test students' knowledge and application of the content presented in the videos. For each module, there are one or two quizzes, each with five to 14 questions. Quiz results reveal areas of student mastery of the video content.

\section{In-Class Exercises}

We have developed three or four in-class exercises for each module that support active learning in the classroom. These in-class exercises strengthen students' understanding of the design process by having them apply knowledge to a new problem, evaluate a completed design scenario, or apply a step in the design process to a team's specific project. In-class exercises that span the range of Bloom's taxonomy were explicitly created.

\section{Implementation}

In fall 2014, these eight of the nine modules were implemented in ENGI 120 at Rice University. The videos and quizzes were integrated into the university course management system. Various analytics on the videos and quizzes are available; this data is reported elsewhere. ${ }^{12}$

\section{Future Work}

The team is in the process of creating an additional six modules, which are focused on the following topics:

- Design process overview

- Understanding customer needs

- Researching a design problem
- Basic physical prototyping

- Testing design solutions

- Failure and iteration in engineering design

\section{Status of Specific Aim \#2 - Evaluate Effectiveness of Flipped Model}

As part of the project, the team is evaluating two major strands of assessment data:

1) Pre- and post-testing of students' knowledge and application of the design process as measured by their critiques of a Gantt chart laying out a 14-week design process.

2) Design team technical memos that document specific steps in the design process, including establishing design criteria, brainstorming solution ideas, and applying Pugh matrices for evaluation. 
The instructors of the first-year design course at Rice University have been teaching ENGI 120 for several years. To date, the team has collected and assessed data on student performance for courses taught using the lecture/team meeting format; dates of collection range spring 2011 through spring 2014. Specifically, the pre- and post-tests using the Gantt chart have been analyzed for several years for the lecture format and are reported elsewhere. ${ }^{13,14}$

Assessment with the flipped classroom model is ongoing since eight flipped classroom modules were launched in ENGI 120 in fall 2014. Preliminary results are published elsewhere. ${ }^{12}$ Data from the flipped classroom model began in fall 2014 and will continue for four semesters.

\section{Status of Specific Aim \#3 - Collaborate to Receive Feedback and Disseminate Materials}

For the materials to be of high value, it has been important to partner early with other members of the first-year engineering community. In addition to presenting at the 2014 and 2015 ASEE meetings, we also presented at the First Year Engineering Education (FYEE) Conference in summer 2014. During that conference, we hosted a workshop. Workshop participants reviewed videos, quizzes and in-class materials, giving us helpful feedback. Key learnings from the workshop included:

- This video series and the idea of a publicly-available repository currently does not exist and, based on positive reception, could gain purchase with peer educators for a freshman engineering education model.

- Use of specific technical terms may limit adoption. For example, courses at some universities use the term "design criteria," whereas others use the term "standard" when referring to the same concept.

- Materials on 'soft skills' such as communication, teaming, and project planning may be more universally transferrable.

- The application of the engineering design process is sufficiently unique for each course to potentially require individualized university-specific introduction videos.

- In-class exercises need more context and definition.

- Quizzes need to address higher levels on Bloom's Taxonomy rather than just recall, understanding, and comprehension.

- There is currently no consensus on best practices to achieve high compliance of participation for out-of-class activities (watching videos, completing quizzes).

Through collaboration with other engineering faculty at the FYEE conference, we created five stand-alone videos:

- Characteristics of high performing teams (Tim Hinds, Michigan State)

- Methods of brainstorming (Courtney Pfluger, Northeastern University)

- Team roles in an engineering design team (Mary Verstraete, University of Akron)

- Interacting with clients (Bill Hulette, Wake Tech Community College)

- Creating a work breakdown structure (AJ Hamlin, Michigan Tech)

Once edited, these videos will become part of the bank of materials. In the future, through more formal collaborations and partnerships, we will gather feedback about the quality and usability of 
the developed materials, including videos and quizzes. Specifically, we are hoping to partner with two schools in fall 2015 to use some of the developed materials.

\section{Acknowledgments}

The team is seeking feedback on developing materials that will be helpful for the academic community teaching engineering design. This work is supported by an NSF DUE grant (\#1244928).

\section{References}

1 V. Jungića, H. Kaurb, J. Mulhollanda, C. Xin, "On Flipping The Classroom In Large First Year Calculus Courses," in International Journal of Mathematical Education in Science and Technology, Vol 10, 2014.

2 L. Abeysekera, P. Dawson, "Motivation and cognitive load in the flipped classroom: definition, rationale and a call for research," in Higher Education Research \& Development, Published online 14 Aug 2014.

3 R. Beichner, "The SCALE-UP Project: A Student-Centered, Active Learning Environment for Undergraduate Programs," National Academy of Sciences, Washington, 2008.

4 "Creating a Culture for Scholarly and Systematic Innovation in Engineering Education," American Society for Engineering Education, Washington, DC, 2009.

5 M. Prince, "Does active learning work? A review of the research," Journal of Engineering Education, vol. 93, no. 3, pp. 1-10, 2004.

6 M. Prince and R. Felder, "Inductive teaching and learning methods," Journal of Engineering Education, vol. 95, no. 2, pp. 123-138, 2006.

7 J. Bishop, M. Verleger, "The Flipped Classroom: A Survey of the Research," in American Society of Engineering Education Conference Proceedings, Atlanta, 2013.

8 L. Barba, "This CFD class is flippin'," Boston University, 1 February 2012. [Online]. Available: http://people.bu.edu/labarba/Lorena_Barba/Blog/Entries/2012/2/1_This_CFD_class_is_flippin.html. [Accessed 21 May 2012].

9 S. Char, C. Collier, "Chalk and Talk Versus Classroom Flipping: Results of a Case Study," in IOSR Journal of Resarch \& Method in Education, Vol 5, Issue 1, pages 24-28, 2015.

10 L. Deslauriers, E. Schelew and C. Wieman, "Improved learning in a large-enrollment physics class," Science, vol. 332, pp. 862-864, 2011.

11 A. Saterbak, M. Embree and M. Oden, "Client-based projects in freshman design," in American Society of Engineering Education Conference Proceedings, San Antonio, TX, June 2012.

12 A. Saterbak, M. Wettergreen, "Teaching Freshman Design Using a Flipped Classroom Model" in Advances in Engineering Education, Special Edition on Flipped Classrooms, extended abstract accepted Feb 2015.

13 A. Saterbak and T. Volz, "Assessing Design Capabilities Following a Client-Based Freshman Design Course," in 4th First-Year Engineering Experience Conference, Pittsburgh, PA, June 2012.

14 A. Saterbak and T. Volz, "Assessing Knowledge and Application of the Design Process," in American Society of Engineering Education Conference Proceedings, Indianapolis, IN, June 2014. 